\title{
FRANÇOIS CHENG, Enfin le royaume. Quatrains
}

\section{Fabio Scotto}

\section{(2) OpenEdition \\ Journals}

\section{Edizione digitale}

URL: https://journals.openedition.org/studifrancesi/45483

DOI: $10.4000 /$ studifrancesi.45483

ISSN: 2427-5856

\section{Editore}

Rosenberg \& Sellier

\section{Edizione cartacea}

Data di pubblicazione: 1 août 2021

Paginazione: 404-405

ISSN: 0039-2944

\section{Notizia bibliografica digitale}

Fabio Scotto, «FRançoIs Cheng, Enfin le royaume. Quatrains», Studi Francesi [Online], 194 (LXV | II) | 2021, online dal 01 septembre 2021, consultato il 15 octobre 2022. URL: http://journals.openedition.org/ studifrancesi/45483 ; DOI: https://doi.org/10.4000/studifrancesi.45483

Questo documento è stato generato automaticamente il 15 octobre 2022.

\section{(c)}

Creative Commons - Attribuzione - Non commerciale - Non opere derivate 4.0 Internazionale - CC BYNC-ND 4.0

https://creativecommons.org/licenses/by-nc-nd/4.0/ 


\title{
FRANÇOIS CHENG, Enfin le royaume. Quatrains
}

\author{
Fabio Scotto
}

\section{NOTIZIA}

FRANÇOIS CHENG, Enfin le royaume. Quatrains, édition introduite et commentée par M.

Bertaud, Genève, Droz, 2020, «Textes littéraires français», 322 pp.

1 Si deve a Madeleine Bertaud, professore emerito dell'Université de Lorraine, questa raffinata edizione commentata di una raccolta risalente alla fine degli anni Cinquanta e apparsa da Gallimard nel 2018 del noto artista e scrittore cinese accademico di Francia. Dopo una premessa bio-bibliografica, nell'«Introduction» (pp. 27-62) la curatrice sottolinea la specificità, nella storia della poesia cinese, della forma ideogrammatica, dal monosillabismo alla ricorrenza in essa dell'ellissi e della metafora, che la rendono assai adatta alla produzione di una specifica magia attraverso il verso, specie con riferimento alla quartina, se essa conobbe nella poesia francese una nuova gioventù dall'Ottocento in poi. Rilevando come tale forma strofica sia infatti preminente nella poesia di François Cheng, specie in modo apparentemente definitivo in quella più recente, Bertaud poi evidenzia, oltre alla scelta formale, le peculiarità concettuali della sua poesia, dalla condizione dell'uomo nell'universo, alla spiritualità, al dilemma morale, all'orfismo.

2 Quanto alla raccolta specificamente presa in considerazione nell'edizione, a partire dalla nozione di nostalgia, intesa come un ritorno all'origine, come rinascita, la curatrice si sofferma sulla spiritualità di Cheng come «vérité incarnée», che anche lo indusse ad assumere il nome occidentale di Francesco D'Assisi, di qui il riferimento al duplice regno, quello della terra e quello dei cieli, che chiama in causa la triade corpospirito-anima, dove l'anima rappresenta «l'unicité de chacun». Poesia dell'essere, poco adatta a una lettura formalista, la lirica di Cheng privilegia una ritmica respiratoria espressa attraverso una varietà metrica votata al canto. Bertaud, che definisce il suo 
commento "pas tout à fait académique» (p. 62), comunque s'accosta ai singoli componimenti con sensibilità e garbo, anche fornendo numerose osservazioni d'interesse filologico che mostrano nel contempo la specificità della raccolta e gli elementi di continuità con le altre opere dell'autore, al fine di evidenziare l'intima ricchezza e coerenza di un percorso fra i più singolari e appartati dell'odierno panorama poetico.

3 Completano il volume un «Index des noms de personnes (auteurs et artistes)» (pp. 315-318), un «Index thématique» (pp. 319-322). 